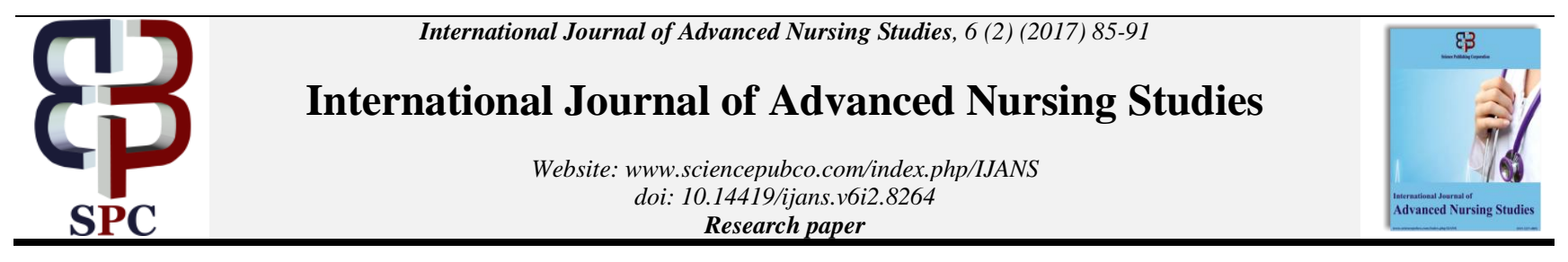

\title{
Lateral violence among nurses at a Jamaican hospital : a mixed methods study
}

\author{
Marilyn F Morrison ${ }^{1}$, Jascinth LM Lindo ${ }^{1,2 *}$, Joyette Aiken ${ }^{1}$, Claudette R. Chin ${ }^{2}$ \\ ${ }^{1}$ The University of the West Indies The UWI School of Nursing 9 Gibraltar Camp Way Mona, Kingston 7, Jamaica \\ ${ }^{2}$ Barry University, CNHS, 11300 NE 2nd Avenue, Miami Florida 33161 \\ *Corresponding author E-mail: jlindo@barry.edu
}

\begin{abstract}
Purpose: In many first-world settings, lateral violence among nurses is pervasive and has been associated with deleterious psychological effects, high staff turnover and negative patient outcomes. This study explored lateral violence among nurses at a Jamaican hospital.

Methods: A fixed concurrent QUAN= QUAL mixed method study design was employed. Data were gathered from 114 registered nurses using the 38-item Briles' Sabotage Savvy self-administered questionnaire and two focus group discussions.

Results: Exposure to lateral violence was reported by $96 \%$ of participants, and 3/4 rated the exposure as moderate to severe. Nurse Managers were the main perpetrators of lateral violence (63\%). Lateral violence created a hostile environment, and half of the nurses surveyed indicated an intent to resign. These survey findings were supported by the focus group discussions which yielded themes inclusive of professional disengagement and erosion of team work.

Conclusion: The high levels of lateral violence reported in this study indicates an urgent need for the implementation of appropriate workplace violence policies. Reported threats to the healthcare system included poor staff retention and professional disengagement.

Highlights:

- Lateral violence among nurses is one of the most damaging issues affecting the progress of the nursing profession and is well studied in the developed world.

- The attributes of the phenomenon of lateral violence in a low and middle-income country are described in this paper.

- Exposure to lateral violence was reported by $96 \%$ of participants, forms of lateral violence appeared to be mainly verbal or emotional and nurse managers were the major perpetrators.

- Assimilated behavior in response to lateral violence among the nurses included professional disengagement, retaliation, avoidance and intent to resign.

- The pervasiveness of lateral violence among the nurses studied indicates the need to implement appropriate workplace violence policies.
\end{abstract}

Keywords: Abuse; Lateral Violence; Sabotage; Bullying; Nursing; Retention

\section{Introduction}

Lateral violence among nurses is one of the most prevalent and damaging issues affecting the progress within the nursing profession today (Blair, 2013). The terms lateral violence and horizontal violence may be used synonymously and are generally described as abuse or hostility within the working environment (Stanley et al. 2007, Wilson et al. 2011). Other terms such as incivility, bullying, relational aggression and workplace violence have also been used to describe the phenomenon of lateral violence (Spiri et al. 2016). Lateral violence can be overt or covert and generally occurs between employees of the same organization. It is often characterized by the presence of several undermining incidents over time (Jackson et al. 2007). Rosen, Koopman, Gabriel, and Johnson (2017) suggest incivility in the workplace is contagious and highlighted the fact that employees who are victims of lateral violence are likely to treat other employees poorly.

The prevalence of lateral violence in the healthcare sector is highest in the nursing profession (Stanley et al. 2007). The Royal College of Nursing (RCN) reported that one in six nurses experience nurse on nurse violence (Royal College of Nursing, 2001) and rates as high as $72 \%$ have been reported in Israel (Natan, Hanukayev, \& Fares, 2011) and Switzerland (Hahn et al. 2010). Within the United States of America, 65-100\% of nurses have been exposed to lateral violence, and many have considered leaving the profession because of its negative impact (McKenna et al. 2003, Johnson 2009, Johnson \& Rea 2009). Among nurses employed as a United States military hospital system, $88 \%$ of respondents reported encountering some sort of incivility in the workplace (Spiri et al. 2016).

Although many nurses experience lateral violence in their professional lives, few speak about it openly. This culture of silence about victimization in the workplace is driven by fear of professional repercussions (Hippeli, 2009). The failure to report incidents of incivility and bullying contributes to the implicit norming of lateral violence among nurses (Blair, 2013). Lateral violence has been associated with increased staff turnover and resultant high cost of healthcare, as qualified nurses often seek alternate work environments in response to workplace incivility (The Joint Commission, 2008). Other institutional consequences of lateral violence include reduced staff morale, low productivity and compromised patient care (Martin et al. 2007, Wilson et al., 2011). Poor communication 
among the nurses and erosion of teamwork, which adversely compromise patient safety are evident in work environments with lateral violence (The Joint Commission, 2008).

\subsection{Theoretical framework}

The severity of nurse on nurse violence is well documented with resultant job dissatisfaction, high levels of absenteeism, professional disengagement and intent to resign (Longo 2007, Johnson \& Rea 2009, Thomas \& Burk 2009, Wilson et al. 2011). Victims of lateral violence may experience: sleep disorders, low self-esteem, apathy and depression (Embree \& White 2010). Weight gain or loss, hypertension, palpitations, irritable bowel syndrome, depression has also been reported (Vessey et al. 2010, Dehue et al. 2012). Embree and White (2010), suggested that causes of lateral violence among nurses include lack of empowerment, authoritarian leadership style, learned hopelessness, negative workplace culture, toxic work environment, suppressed anger, shrinking resources, conflict avoiding culture, low self-esteem, personal behavior and strict hierarchical system.

Freire (1970) Oppressed Group Model or oppression theory describes the hegemony of medicine relative to the predominantly female nursing profession and provides a theoretical framework for understanding lateral violence. In this theory, the oppressor achieves control by humiliating and/or denigrating the dignity of colleagues, and over time, the oppressed group imitates their oppressors (Thomas \& Burk 2009). Lim and Bernstein (2014, p. 124) describe a long history of professional abuse among nurses. The team cited Florence Nightingale's caustic manner, difficult domineering personality as contributory to an intimidating work space.

\subsection{Background}

Strategies developed to address lateral violence among nurses globally involve the acknowledgment of its existence and the implementation of a zero-tolerance approach by employers (RNAO, 2008). Policy development should be driven by relevant evidence. Two small studies on lateral violence in Jamaica were identified and none in the wider Caribbean. Aiken et al. (2012) qualitative study of 16 nurses employed at two urban hospitals in Jamaica found nurses frequently experienced and witnessed lateral violence in the local practice setting. These nurses reported it was pervasive and mainly in the form of verbal abuse. High level of workplace violence was also reported among health workers studied at one Jamaican hospital (Lindo et al. 2012). In this study, researchers aimed to develop strategies to mitigate workplace violence. Through focus group discussions which included nurses, doctors, radiologist and pharmacists, it was revealed that lateral violence was pervasive among enrolled assistant nurses (similar to licensed practical nurses in the North America) and registered nurses.

The literature confirmed the existence of lateral violence in Jamaican hospitals and highlighted the need for additional research. Aiken et al. (2012) lamented the fact that the phenomenon had not been subjected to a pragmatist approach. This approach which allows the triangulation of quantitative and qualitative method is likely to offer greater insight into the phenomenon in local practice settings (Creswell, 2013). This study sought to explore lateral violence among nurses in a Jamaican hospital. Specifically, the study determined the level of exposure to lateral violence using quantitative methods and gained additional insight regarding the characteristics and impact of the phenomenon at the institution using qualitative methods.

\section{Methods}

\subsection{Study design}

A fixed concurrent mixed (QUAN=QUAL) methodology study design was selected. The study included the piloting of a quantitative cross-sectional survey and two focus group discussions was conducted (completed in May -June, 2012). Qualitative and quantitative data are triangulated in the discussion section of the paper.

\subsection{Population and setting}

The study was conducted at a quasi-government, tertiary level, 579bed teaching hospital in Kingston, Jamaica. The hospital serves patients from across the island and the wider Caribbean. A cadre of 750 nurses completed the multidisciplinary, professional, healthcare team employed at the selected study site.

\subsection{Sample size and sample selection}

The sampling frame included 550 Registered Nurses deployed in the following areas at the institution: Surgical and Medical units, Accident \& Emergency Department, Out Patient Department and Minor Operating Theatre, Intensive Care Unit, Recovery Room, the Private Wing, and the Central Sterilizing Department. Raosoft Inc (2004), yielded a recommended sample size of 227 nurses with parameters of 5\% margin error, Confidence Interval of $95 \%$ and distribution of 50\%. A pilot study inclusive of at least 50\% (114 registered nurses) of the recommended sample size was undertaken in partial fulfillment of a Master of Nursing degree $\mathrm{MScN}$ ).

Study participants were stratified into groups of nurse managers and non-managers to facilitate purposive sample recruitment for two focus group discussions. Twenty-six nurses who reported exposure to lateral violence were recruited to participate in two equal groups.

\subsection{Instrumentation}

A self-administered questionnaire, including a 5 item demographic data form (age, sex, current job category, years of experience in this job category, and area of practice) and Part I of Briles' (1994) Sabotage Savvy Questionnaire (SSQ) were used. The Briles' (1994) Sabotage Savvy Questionnaire measures occurrences of lateral violence (LV) and the nurses' knowledge of LV (Dunn, 2003). The SSQ has reported Cronbach alpha scores of 0.86 and 0.72 which indicate strength and internal consistency reliability among nurses studied in the US (Dunn, 2003). Part 1 of the SSQ has 32 questions designed to determine if the study participant had ever been sabotaged or had knowledge of sabotage in the work setting; and to describe the presence or absence of acts of sabotage both as victim and perpetrator. Responses of "no," "not sure," or "yes" were sought for each question, and the frequencies of each response tallied. The Cronbach alpha score for the SSQ in the study population was 0.820 .

\subsection{Data collection}

Potential participants were informed of the study and presented with sealed envelopes inclusive of consent form, questionnaires and an envelope for the return of completed instruments, which were collected after a period of one week. The signed consent forms were separated from the completed questionnaires and stored in a locked cabinet in the Principal Investigator's office.

\subsection{Data analysis}

Quantitative data were analyzed using the Statistical Package of the Social Sciences (SPSS®) Version 17 for Windows ${ }^{\circledR}$. Descriptive statistics were used to summarize demographic responses. Chi Square analysis determined differences between categorical variables; and Pearson's correlation coefficient determined the strength and direction of relationships among variables.

\subsection{Qualitative approach}

The Consolidated Criteria for Reporting Qualitative Research (COREQ) guided the report of the descriptive phenomenological 
qualitative aspects of the study. Consenting registered nurse managers and non-managers participated in two separate focus group discussions. Permission to audiotape the discussion was obtained from the participants who were assigned pseudonyms. They were advised to share only information with which they were comfortable. The focus group discussions were led using a semi-structured interview guide designed to explore the participants' experiences of lateral violence and lasted approximately ninety minutes. At the end of each session participant were asked by the researcher to verify the accuracy of the summarized content of the discussion. This was done to increase the trustworthiness and credibility of the findings. A team of three researchers participated in the analysis of the qualitative transcript (two supervisors and the researcher) which included reflections geared at minimizing bias through bracketing and journaling. The audio taped qualitative data were transcribed verbatim and reviewed twice for improved insight. The data transcribed included quotations, which at times were reflective of the use of the Jamaican dialect; these are reported verbatim in the study. Emerging themes and repeated patterns were grouped into concepts for interpretation and analysis (Braun \& Clarke 2006).

\subsection{Ethical considerations}

The study was approved by the University Hospital of the West Indies/ University of the West Indies, Faculty of Medical Sciences/ (UHWI/UWI/ FMS/) Ethics Committee and permission to conduct the study was granted by the hospital administration. Written informed consent was obtained from all participants who were reminded of their right to withdraw from the study at any time. Given the nature of the study, no names or identifiable markers were recorded. This heightened confidentiality and provided anonymity for the participants who completed the survey.

\section{Results}

The response rate of the study was $93 \%(n=107 / 114)$ and almost all the participants were females (93\%). Most of the participants were $20-30$ years $(57 \%)$. More than a half of the sample was staff nurses (54\%); $31 \%$ were specialist nurses and $15 \%$ were managers (charge nurses and directors). Most of the participants (58.7\%) had been employed in their current position for a period of three or more years (Table 1).

The respondents were assigned across multiple units at the hospital, including the intensive care unit (23.6\%), main operating theatres/recovery unit/the private wing $(20.8 \%)$, medical units $(20.8 \%)$, general surgery and obstetrics and gynecology units (18.9\%). The Accident and Emergency Department, the Outpatient and Minor Operating Theatre together accounted for $17.9 \%$ of the study population.

\subsection{Lateral violence among the nurses studied}

Lateral violence was pervasive, with $96 \%$ of the participants reporting that they experienced abuse and $72 \%$ of that number reported moderate to severe levels of abuse at work. More than half of the nurses $(52.6 \%)$ who were employed for $0-3$ years reported moderate abuse/sabotage or bullying, while equal proportions reported minimal and severe abuse $(23.7 \%)$. The prevalence of abuse/sabotage/bullying was not associated with the nurses' job title $(\chi 2=$ 1.300; $\mathrm{p}=0.861)$; period employed to current position $(\chi 2=2.317$, $p>0.05)$ or the area to which nurses were assigned $(\chi 2=5.951 ; p=$ $0.653)$.

Most respondents (55\%) used strategies such as avoidance in response to lateral violence (Table 2). The results also indicated that $53.7 \%$ of nurses surveyed would resign as a response to lateral violence. A large cohort (67\%) wished managers would formally warn perpetrators, and more than a half of the participants (56\%) lost respect for managers who did not address the perpetrators of lateral violence. The majority of participants $(66.7 \%)$ believed persons who committed acts of abuse gained favor with administration because of these acts.

Table 1: Demographic Profile of Respondents

\begin{tabular}{|c|c|c|}
\hline & $\begin{array}{l}\text { Frequency } \\
\text { (n) }\end{array}$ & $\begin{array}{l}\text { Percentage } \\
(\%)\end{array}$ \\
\hline \multicolumn{3}{|l|}{ Gender } \\
\hline Male & 7 & 7.0 \\
\hline Female & 100 & 93.0 \\
\hline \multicolumn{3}{|l|}{ Age Group } \\
\hline $20-30$ & 61 & 57.0 \\
\hline $31-40$ & 31 & 31.8 \\
\hline $41 \mathrm{yrs}$ or older & 15 & 11.2 \\
\hline \multicolumn{3}{|l|}{ Educational Level } \\
\hline Baccalaureate & 72 & 97.3 \\
\hline Graduate & 2 & 2.7 \\
\hline \multicolumn{3}{|l|}{ Unit } \\
\hline Intensive Care Unit & 24 & 23.0 \\
\hline Main OT* Recovery/Private Wing & 22 & 20.8 \\
\hline Medical Units & 22 & 20.8 \\
\hline Surgery /Obstetrics\& Gynecology & 20 & 18.9 \\
\hline $\begin{array}{l}\text { Accident \& Emergency / Minor } \\
\text { OT* }\end{array}$ & 20 & 18.9 \\
\hline \multicolumn{3}{|l|}{ Time on Unit } \\
\hline 3 years or less & 43 & 41.3 \\
\hline$>3$ years & 61 & 58.7 \\
\hline \multicolumn{3}{|l|}{ Job title/Levels 1-3 } \\
\hline Level 1 (General RN) & 54 & 55.7 \\
\hline Level 2 (Specialist Nurse) & 32 & 33.0 \\
\hline Level 3 (Charge Nurse & 11 & 11.3 \\
\hline \multicolumn{3}{|l|}{ Level of LV Experienced* } \\
\hline None/ Minimal abuse & 27 & 28.1 \\
\hline Moderate abuse & 41 & 42.7 \\
\hline Severe abuse & 28 & 29.2 \\
\hline
\end{tabular}

*OT $=$ Operating Theatre, $\mathrm{LV}=$ Lateral Violence

Table 2: Respondents' Response to Lateral Violence

\begin{tabular}{ll}
\hline Questions about lateral violence & $\mathrm{N}(\%)$ \\
\hline Participants were asked to respond yes or no to the following & Yes \\
questions & 80.6 \\
Has lateral violence caused you stress? & $(50)$ \\
& 66.7 \\
Would you like management to warn perpetrators? & $(46)$ \\
Do you lose respect for manager who does not deal with per- & 56.2 \\
petrator of lateral violence? & $(50)$ \\
Do you do everything to avoid perpetrators of lateral vio- & 55.1 \\
lence? & $(49)$ \\
Would you resign because of lateral violence? & 53.8 \\
& $(57)$ \\
Do you dread coming to work due to lateral violence? & 52.4 \\
Did lateral violence enhance the reputation of the perpetra- & $(55)$ \\
tor? & 46.0 \\
\end{tabular}

\subsection{Qualitative findings}

The qualitative descriptions elucidated lateral violence in the Jamaican context. Each participant of the focus group discussions had either experienced or observed lateral violence and provided descriptions of the phenomenon including nurse's response to lateral violence.

The participants suggested that persons, who were older, at a supervisory level (managers and charge nurses) and nurses trained at the baccalaureate level, were more likely to be perpetrators of lateral violence. They described the features of the abuse to include shouting, gossiping, public criticism and embarrassment; isolation/silent treatment; backbiting; iniquitous off duty scheduling and patient assignments; and prevention of access to lucrative over-time sessions. One nurse described her experience with bullies “... they block your promotion and training opportunities; they use the off duty to allocate punishment... and (they) hit you in the pocket too, as you are not given premium sessions..."

A young nurse with less than three years' experience lamented about the iniquitous patient assignments "... You are assigned the 
barrier nursed patient every day, or they give you the most difficult patient to work with every day...and they take the light patients..."

\subsection{Categories and themes from focus group discussions}

The content of the transcripts was placed into broad categories relating to the professional and personal responses of lateral violence (reflected in Figure 1.).

\subsection{Professional responses to lateral violence}

Three themes related to professionalism emerged: professional disengagement, erosion of teamwork and poor staff retention. Professional disengagement appeared to be most dominant, typified by statements such as 'I cannot wait until the eight hours end! It mus end!'; 'You lose your drive to work'; "I do my shift and go home, nothing more; I ignore them".

In response to perceived acts of lateral violence, participants were willing to risk administrative rebuke by being deliberately late or by intentionally refusing overtime work when the bullies worked in charge of the unit: "I deliberately come to work late to get back at them"; "I take a mental health day and absent myself from duty." Some nurses were so disillusioned and hurt that they could not bear to think of others being so hurt, and made comments like, "I would never recommend a relative/friend to the nursing profession". One nurse reported: "A colleague said if her daughter wanted to become a nurse, she would beat her".

Participants described a gradual physical and psychological withdrawal, and articulated intent to resign as common responses to the abuse. Each non-manager expressed intent to resign in response to lateral violence. On the other hand, managers were less likely to do so as they felt they had invested too much in their current job. One nurse manager shared with disbelief, "One nurse was ready to pay her bond and leave because of the bullying". Non-managers insisted that the experience of lateral violence was "... a major factor in deciding to stay or leave." One participant shared, "I cannot wait to get the next boat out of this place to a better environment". Yet another stated, "Look at the rate of resignations from here, it's not all about the money, it's the distress".
These statements also reflected the resultant issue of staff retention at the institution.

Lateral violence appeared to affect the profession by eroding teamwork among the nurses. This was manifested with the avoidance of the perpetrators at all costs, sometimes to the extent of omitting common courtesies such as saying, "Good morning", for fear of being ignored or embarrassed. Participants described issues of lack of trust and poor communication and made statements such as "I don't trust working with them" and "There is no teamwork here". Distrust of nursing administration was expressed by the non-managers. They perceived nursing administration as enabling perpetrators of lateral violence when senior nurses were commended for 'managing' their staff.

\subsection{Personal responses to lateral violence}

Personal responses to lateral violence included aggression, vulnerability and stress responses. Coping responses varied as some nurses embraced lateral violence as a vehicle for career advancement. Nurses in both focus groups reported they observed displays of aggression in response to lateral violence in silence. Participants' noted negative personality changes in themselves and in other victims of lateral violence: "You start to get bitter like them". They harbored thoughts of physically injuring the abuser, or damaging their property: "Sometimes I feel like puncturing their tires...". The effects of lateral violence on the psyche of the nurses appeared farreaching. They expressed vulnerability, fear, depression, emotional depletion and loss of self-esteem. "It takes a toll on you; you gear up for a fight everyday". "The tension is heavy at work... It's like there is acid in the air especially when you work in an enclosed environment". Some participants attributed their illness (high blood pressure, fatigue and premature grey hair) to internalized stress associated with lateral violence. The nurses also felt that perpetrating violence was a vehicle for professional advancement. For example, "Nurses are fighting for a charge nurse position... the perpetrators get fast tracked for promotion." This sometimes led to a level of acceptance, while they contemplated the way forward.

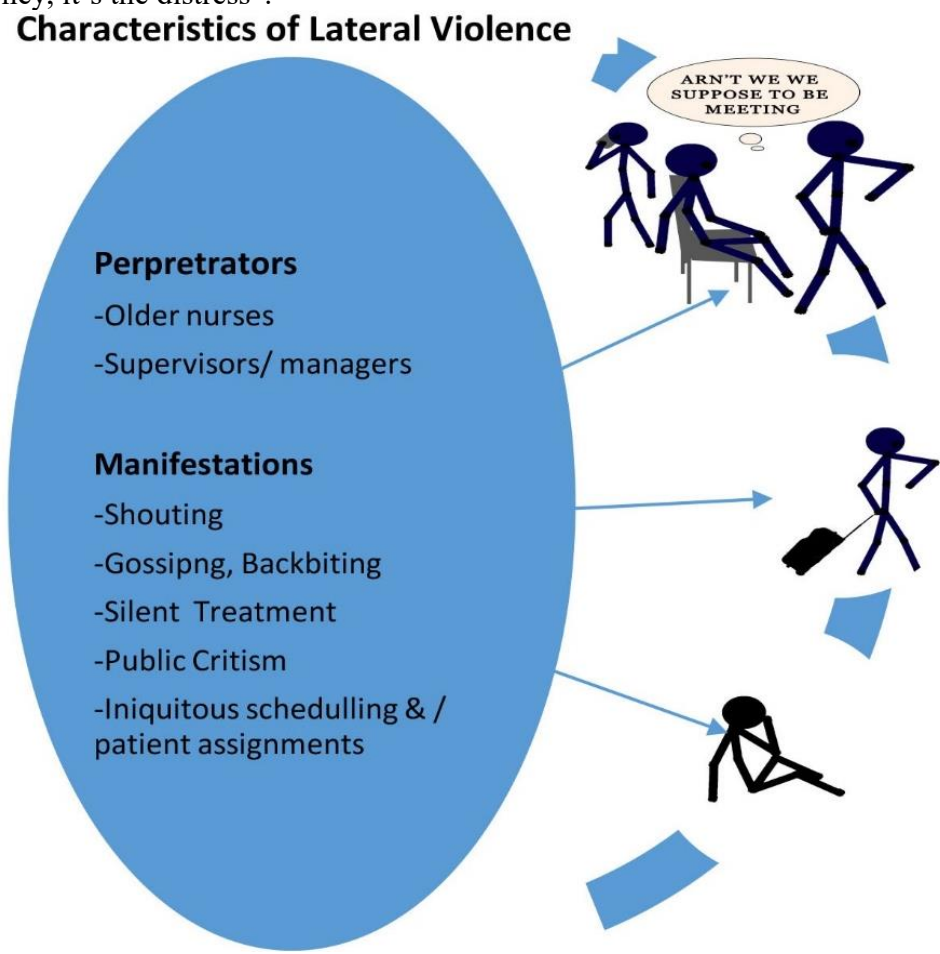

Professional Response

-Disengagement at work

-Erosion of team work

-Poor staff retension

-Poor communication

\section{Personal Response}

-Retaliation Vs Vulnerability

-Avoidance /deliberate absence

-Resignation /migration

-Stress Responses

-Mental \& physical health issues

\section{Coping Response}

-Acceptance of incivility

Right of passage

-Vehicle for career advancement

-Contemplation

Wieghing pros vs cons

Fig. 1: Summary of Findings from the Focus Group Discussions. 


\section{Discussion}

This study sought to explore lateral violence among nurses in a Jamaican hospital. The findings of the quantitative and qualitative aspects of the study were triangulated for a discussion around lateral violence in the Jamaican context. In this study, lateral violence was pervasive, with nine of ten nurses reporting abuse of mainly moderate to severe levels. This was comparable to global rates of nonphysical violence (Spector et al. 2014), but, significantly higher than the $27 \%$ of members of the Washington State Emergency Nurses Association who reported being bullied (Johnson \& Rea 2009). The qualitative findings of this study also suggested lateral violence was pervasive; described as a common occurrence. Underlying factors, which may perpetuate lateral violence, may lie outside of characteristics such as experience, or clinical setting, but may be rooted in professional tradition, societal violence or other factors such as acquisition of power (Blair, 2013, Spector et al 2014). The high prevalence of lateral violence among these Jamaican nurses may be reflective of the pervasiveness of violence in the broader Jamaican society (World Bank, 2009). Societal violence may have prompted the acceptance of lateral violence described in the focus group discussions.

The focus group participants contextualized the characteristics of lateral violence as having education and earning opportunities blocked, being neglected, or being given too much responsibility without adequate support. Similar findings were reported among new Registered Nurses in a prior Jamaican study (Aiken et al. 2012) and in New Zealand (McKenna et al. 2003). Perpetrators of lateral violence in this study gave demeaning tasks, disproportionate patient load, unfavorable shift assignments or what participants described as "the worse patients", "under the disguise of delegating". For example, a bullied nurse would be frequently assigned to care for the "barrier-nursed patient". This relational act of ostracism can destroy the team work and has been described by Dellasega (2009) and Briles (2007).

Another feature of lateral violence uncovered from the focus group discussions was monetary sabotage. This was described as failure to grant overtime sessions to bullied staff when there was a premium rate being paid - for example on weekends and public holidays. Monetary sabotage can be highly consequential for the Jamaican nurse, whose base earnings are extremely low, and who depends on weekly overtime sessions to supplement their income. Study participants felt the 'premium' sessions (weekends and public holidays) where double rates were paid, were reserved for "friends and favored people", and as such constituted a violent, exclusionary act. It would appear that the Jamaican health system has facilitated this practice given the prolonged and persistent shortage of registered nurses (World Bank 2009). Furthermore, despite strategies such as increased training of nurses, retention rates remain low. These findings underscore the need for national policy regulations to address the problems identified.

While low wages are a major reason for migration among Jamaican nurses, interpersonal relationships and the working environment also played a substantial role in their decision to leave the profession (Hewitt 2005, Scarlett 2009). Current international evidence suggests nurses employed in geriatric facilities, psychiatric and Accident and Emergency units have higher rates of workplace violence (Spector et al. 2014). In this survey exposure to lateral violence did not differ across units, however, focus group participants believed nurses who worked in sensitive and high- stress closed units such as the Operating Theatre and Intensive Care Unit endured more intense levels of lateral violence. The perception that lateral violence experiences can be exacerbated has also been reported in other local studies in closed units has been reported (Bartholomew 2006, Dunn 2003).

Participants often responded to lateral violence with avoidance or failure to do anything about the occurrence. Blair (2013) describes avoidance as a common response to lateral violence among nurse leaders and Stanley et al. (2007) reported that more than half of nurses in their study, did nothing in response to lateral violence.
This code of silence was pervasive and up to $50-80 \%$ of lateral violence events go unreported (Longo 2007, Geig, 2010) and although intended to be a self-protecting behavior, this silence erodes the psychological health of both the observer and victim of lateral violence. The study also concluded that speaking with a manager about the problem was usually a 'dead end'; a finding that was also explicated in the focus group discussions in this study. Nurses' failure to report lateral violence is exacerbated by the absence of a clear workplace violence policy (Edward et al. 2014) and failure to empower junior nurses to speak up in response to lateral violence during their undergraduate preparation.

Findings from the UK indicate that bullying among nurses is learned behavior; in this instance, from personal experiences (Lewis, 2006). However, the overwhelming majority of nurses surveyed in the quantitative arm of the study $(93 \%)$ denied having bullied a fellow nurse. Expressions of the desire to commit physical acts of violence in response to lateral violence and bullying were reported, although there were no reports of actual physical confrontations. Stanley et al. (2007), suggested that these responses arose when the observer or victims have internalized the anger. Additionally, nurses who were non-managers used intentional work absence and avoidance as their retaliation strategy, particularly when they were scheduled to work with the bully. Being absent creates undue hardship for other nurses in hospitals, particularly in developing countries, as inadequate staffing is pervasive (especially on night and evening shifts).

Study participants viewed the perpetration of lateral violence as unprofessional behavior that was often overlooked; and seen as the norm within the profession (Bartholomew 2006, Thomas \& Burk 2009). Work environments with high levels of lateral violence often exhibit professional disengagement and poor communication (Blair, 2013). Poor communication and professional disengagement have been cited as the root-cause of almost $60 \%$ of harm to patients and underscores the urgent need to address the issue of lateral violence (Purpora \& Blegen 2012, Blair 2013). The quality of the relationship among nursing staff plays a significant role in retaining nurses (Trybou et al. 2015). Resigning appears to be a common response to workplace violence in both Canada and the United States (Griffin 2004, Rocker 2008, Wilson et al. 2011). Wilson et al. (2011), claimed among nurses studied across 130 hospitals in the US, four of ten nurses indicated their intent to leave their current position and the $40 \%$ were definitely going to leave because of horizontal/lateral violence.

During the focus group discussion inclusive of non-managers, the concept of "professional disengagement" among the victims of lateral violence was introduced. The participants described instances of self-reported absences and verbal withdrawal where social courtesies such as 'good morning' were not granted. Instead, the nurses' attitude was "just do the work and leave".

In the presence of this kind of incivility, the nurse may not be fully engaged at work; resulting in the erosion of teamwork and suboptimal patient care. This is a feature of lateral violence which is highlighted by The Joint Commission (2008). According to Spiri et al. (2016), 38\% of nurses in a military health system reported asking another colleague to talk to the perpetrators for example when there was need to clarify an order. The stifling of nursing initiatives and innovation is likely to occur when communication is less than optimal between the health professionals (Stanley et al. 2007). The transcripts from both focus group discussions described increased testimonials of explosive tension in the workplace, evidenced by reported verbal assaults, thus creating a hostile work environment.

\subsection{Implications for practice}

This study has major implications for practice as the level of professional disengagement, impaired communication and significant erosion of team work reported is likely to present safety issues and reduced quality of patient care. Hostile work environments may impact the nurses' health and their intent to leave their positions [especially among new nurses] (Budin et al. 2013). The focus group 
participants and more than half of the nurses surveyed reported an intention to leave their jobs because of lateral violence. This poses an immediate threat to succession planning and staff retention at the institution studied. These findings are aligned with the 2009, World Bank Report which claims three of four nurses trained in Jamaica migrate to industrialized nations, resulting in a shortage of nurses. The report also purported that the shortage of nurses affected the quality of healthcare delivered in the island.

\section{Limitations}

Limitations of this study include the small scale of the study, the use of a convenience sampling method and the variability in the types of units sampled. The findings of the focus group discussions suggest that capturing the level of education/qualification of nurses quantitatively, may have enhanced data analysis. This was not done.

\section{Conclusion}

The findings of this study suggest a high prevalence of lateral violence among respondents and that nurse managers were the most common perpetrators. It also appeared that lateral violence contributed to the erosion of professionalism among the nurses. Urgent administrative attention and the introduction of requisite workplace violence policies are indicated.

This new knowledge brings greater insight into lateral violence and its effect on nursing professionals in a lower middle-income country and presents an opportunity for targeted interventions in the Jamaican healthcare setting. Such interventions have resulted in increased productivity, improved quality of patient care, reduced absenteeism and fewer resignations among registered nurses in other settings (Griffin 2004, Martin et al. 2007, Wilson et al. 2011). Finally, undergrad nurse educators should ensure content relevant to the prevention of lateral violence, promotion of professionalism, and nurse advocacy is added to the nursing curricula.

\section{References}

[1] Aiken J, Lindo J, Nevins D, Pounall V, Thomas M, Baker -Reid C \& Ward E (2012) Lateral Violence in Nursing: The experience in two urban hospitals in Jamaica. In I. Needham, McKenna, K, Kingma, M \& Oud, N, (Ed.), Third International Conference on Violence in the Health Sector Linking local initiatives with global learning (pp. 110113). Amsterdam, the Netherlands: Kavanah.

[2] BartholomewK (2006) ending nurse-to-nurse hostility: Why nurses eat their young and each other. Marblehead, MA: HC Pro, Inc.

[3] Blair PL (2013) Lateral violence in nursing. Journal of Emergency Nursing, 39(5), e75-e78. https://doi.org/10.1016/j.jen.2011.12.006.

[4] Braun V \& Clarke V (2006) Using thematic analysis in psychology. Qualitative Research in Psychology, 3(2), 77-101. https://doi.org/10.1191/1478088706qp063oa.

[5] Briles J (2007) Snakes at the nursing station. American Nurse Today, 2(8), 52-53.

[6] Budin WC, Brewer CS, Chao YY \& Kovner C (2013) Verbal abuse from nurse colleagues and work environment of early career registered nurses. Journal of Nursing Scholarship, 45(3), 308-316. https://doi.org/10.1111/jnu.12033.

[7] Dehue F, Bolman C, Völlink T \&Pouwelse M (2012). Coping with bullying at work and health related problems. International Journal of Stress Management, 19(3), 175-197. https://doi.org/10.1037/a0028969.

[8] Dellasega CA (2009) Bullying among nurses. AJN the American Journal of Nursing, 109(1), 52-58. https://doi.org/10.1097/01.NAJ.0000344039.11651.08.

[9] Dunn H (2003) Horizontal violence among nurses in the operating room. AORN Journal, 78(6), 977-988. https://doi.org/10.1016/S0001-2092(06)60588-7.

[10] Edward K, Ousey K, Warelow P \&Lui S (2014) Nursing and aggression in the workplace: a systematic review. British Journal of Nursing, 23 (12), 653-659. https://doi.org/10.12968/bjon.2014.23.12.653.

[11] Embree JL \& White AH (2010) Concept analysis: Nurse-to-Nurse lateral violence. Paper presented at the Nursing Forum. https://doi.org/10.1111/j.1744-6198.2010.00185.x.
[12] Freire P (1970) Pedagogy of the oppressed (MB Ramos, Trans.). New York: Continuum, 2007

[13] Geig E (2010) Health policy report: Workplace violence legislation. Ohio Nurse Review, 85(1), 6.

[14] Griffin M (2004) Teaching cognitive rehearsal as a shield for lateral violence: An intervention for newly licensed nurses. The Journal of Continuing Education in Nursing, 35(6), 257-263.

[15] Hahn S, Müller M, Needham I, Dassen T, Kok G \&HalfensRJ (2010) Factors associated with patient and visitor violence experienced by nurses in general hospitals in Switzerland: a cross-sectional survey. Journal of Clinical Nursing, 19(23-24), 3535-3546. https://doi.org/10.1111/j.1365-2702.2010.03361.x.

[16] Hewitt H (2005) Managed Migration: The University of the West Indies School of Nrsing response The Jamaican Nurse, 43, 27-31.

[17] Hippeli F (2009) Nursing: does it still eat its young, or have we progressed beyond this? Paper presented at the Nursing Forum. https://doi.org/10.1111/j.1744-6198.2009.00141.x.

[18] Jackson D, Firtko A \& Edenborough M (2007) Personal resilience as a strategy for surviving and thriving in the face of workplace adversity: a literature review. Journal of Advanced Nursing, 60(1), 1-9. https://doi.org/10.1111/j.1365-2648.2007.04412.x.

[19] Johnson SL (2009) International perspectives on workplace bullying among nurses: a review. International Nursing Review, 56(1), 34-40. https://doi.org/10.1111/j.1466-7657.2008.00679.x.

[20] Johnson SL \& Rea RE (2009) Workplace bullying: Concerns for nurse leaders. Journal of Nursing Administration, 39(2), 84-90. https://doi.org/10.1097/NNA.0b013e318195a5fc.

[21] Lewis SE (2006) Recognition of workplace bullying: A qualitative study of women targets in the public sector. Journal of Community $\begin{array}{llll}\text { \& Applied Social Psychology, } 16 & \text { (2), 119-135. }\end{array}$ https://doi.org/10.1002/casp.850.

[22] Lim FA\& Bernstein I (2014) Civility and workplace bullying: Resonance of Nightingale's persona and current best practices. Nursing Forum, 49(2), 124-129. https://doi.org/10.1111/nuf.12068.

[23] Lindo J, Nevins D, Aiken J, Pounall V, Thomas M, Reid-Baker C $\&$ Ward E(2012) Strategies for the mitigation of workplace violence in a Jamaican hospital In I. Needham., K. McKenna, M. Kingma\& N. Oud (Eds.), Third International Conference on Violence in the Health Sector Linking local initiatives with global learning (pp. 359 362). Amsterdam, The Netherlands: Kavanah

[24] Longo J (2007) Horizontal violence among nursing students. Archives of Psychiatric Nursing, 21(3), 177-178. https://doi.org/10.1016/j.apnu.2007.02.005

[25] Martin A, Gray C \& Adam A (2007) Nurses' responses to workplace verbal abuse: a scenario study of the impact of situational and individual factors. Research and Practice in Human Resource Management, 15(2), 41-61

[26] McKenna BG, Smith NA, Poole SJ \& Coverdale JH (2003) Horizontal violence: Experiences of registered nurses in their first year of practice. Journal of Advanced Nursing, 42(1), 90-96. https://doi.org/10.1046/j.1365-2648.2003.02583.x.

[27] Natan MB, Hanukayev A \& Fares S (2011) Factors affecting Israeli nurses' reports of violence perpetrated against them in the workplace: A test of the theory of planned behaviour. International Journal of Nursing Practice, 17(2), 141-150. https://doi.org/10.1111/j.1440172X.2011.01919.X.

[28] Purpora C \&Blegen MA (2012) Horizontal violence and the quality and safety of patient care: A conceptual model. Nursing Research and Practice, 2012. https://doi.org/10.1155/2012/306948.

[29] Raosoft Inc. (2004). Sample size calculator. Retrieved June 15, 2012, from www.raosoft.com/samplesize.html

[30] RNAO (2008) Position Statement: Violence against nurses - 'Zero' tolerance for violence against nurses and nursing students. Retrieved June 20, 2012, from http://rnao.ca/policy/position-statements/violence-against-nurses

[31] Rocker CF (2008) Addressing nurse-to-nurse bullying to promote nurse retention. Online Journal of Issues in Nursing, 13(3). doi 10.3912/ojin.vol13no03ppt05

[32] RosenCC, Koopman J, Gabriel AS \& Johnson RE (2017) Uncivil behaviour in the workplace causes mental fatigue and is contagious. LSE Business Review.

[33] Royal College of nursing (2001) dealing with bullying and harassment at work: A guide for RNC Members. RNC, London

[34] Scarlett BL (2009) Factors influencing nursing as a career choice and the retention of nurses in the profession in Jamaica. (Doctoral Dissertation).

[35] Spector PE, Zhou ZE \& Che XX (2014) Nurse exposure to physical and nonphysical violence, bullying, and sexual harassment: A quantitative review. International Journal of Nursing Studies, 51(1), 72 84. https://doi.org/10.1016/j.ijnurstu.2013.01.010. 
[36] Spiri C, Brantley M \& McGuire J (2016) Incivility in the workplace: A study of nursing staff in the Military Health System. Journal of Nursing Education and Practice, 7(3), https://doi.org/10.5430/jnep.v7n3p40.

[37] Stanley KM, Martin MM, Michel Y, Welton J M \& Nemeth LS (2007) Examining lateral violence in the nursing workforce. Issues in Mental Health Nursing, 28(11), 1247-1265. https://doi.org/10.1080/01612840701651470.

[38] The Joint Commission $(2008,2016)$ Behaviors that undermine a culture of safety. Retrieved June 30, 2017, from http://www.jointcommission

[39] Thomas SP \& Burk R (2009) junior nursing students' experiences of vertical violence during clinical rotations. Nursing Outlook, 57(4), 226-231. https://doi.org/10.1016/j.outlook.2008.08.004.

[40] TrybouJ, Malfait S, Gemmel P \& Clays E (2015) Nursing staff and their team: Impact on intention to leave. International Nursing Review, 62(4), 489-496. https://doi.org/10.1111/inr.12216.

[41] Vessey JA, DeMarco R \&DiFazio R (2010) Bullying, harassment, and horizontal violence in the nursing workforce the state of the Science. Annual Review of Nursing Research, 28(1), 133-157. https://doi.org/10.1891/0739-6686.28.133.

[42] Wilson BL, Diedrich A, Phelps CL \& Choi M (2011) Bullies at work: The impact of horizontal hostility in the hospital setting and intent to leave. Journal of Nursing Administration, 41(11), 453-458. https://doi.org/10.1097/NNA.0b013e3182346e90.

[43] World Bank (2009) Crime, violence, and development: Trends, costs, and policy options in the Caribbean. A joint report by the United Nations Office on Drugs and Crime and the Latin America and the Caribbean Region of the World Bank. Washington: DC. 